\title{
EL ESTATUTO DE LA ESCRITURA EN LA FILOSOFÍA CARTESIANA
}

Isabel Balza

Analizaré qué diferente concepción de la escritura filosófica subyace a dos estrategias metódicas; a saber: la representada por lo que Maria Zambrano llama 'confesión' y la que se desprende del método cartesiano.

En el Discsirso del método Descartes trataba de justificar, no tanto por qué escribia, sino más bien por qué publicaba. No obstante, a la hora de enumerar las razones de la publicación encontramos también, confundido con estas, el modo en el que se representaba su escritura. Descartes impone aqui una regla; a saber: escribir siempre como si fuera a publicar. No obstante, el que sepamos que no se decidiera a publicar todo lo que escribió hace sospechar que aquello que le exigia a la escritura no llegó siempre a ser alcanzado. Así, en el Discurso declaraba su solo reconocimiento - ante sus futuros lectores - para aquello publicado con su consentimiento. ${ }^{1}$ La cuestión es entonces la siguiente: ¿cuál era la exigencia cartesiana respecto a lo escrito? En el resumen que precede a las Afeditaciones responde, en cierto modo, a esta pregunta: su tarea era la de no escribir nada - en este caso, no publicar nada- de lo que no se tuvieran demostraciones muy exactas. 2 Pero, por otra parte, para poder conseguir las demostraciones era necesario recurrir a la escritura, porque "chacun doit expérimenter s il se ressouvient bien [las demostraciones]" y "qui a des doutes sur ce point doit s'aider de l'icriture et de semblables adjwants"; 3 es decir, que la escritura, al remediar la mala memoria, va a jugar un papel dentro del método. Dado que el pensamiento es, como dice en las Regulae, un «moutvement contimu et nulle part interrompu de la penséen, 4 la escritura deberá trazar el orden y continuidad propios del pensar, que la debilidad de la memoria impide retener. ${ }^{5}$ La escritura debe sostener la meditación atenta que Descartes persigue y prescribe.

Sin embargo, aunque la escritura forma parte del método, pues ayuda a distinguir lo verdadero de lo falso y remedia la debilidad de la memoria, Descartes muestra siempre una desconfianza hacia aquélla. Desconfianza que parte de una escisión: la escisión entre pensamiento y escritura, y que podemos encontrar supuesta cuando declaraba a propósito de su Tratado del Mundo: "j'ai eu dessein d'y comprendre tout ce que je pensais savoir, arant que de l'écrire, touchant la nature des choses matérielles". Se trata de pensar antes que de escribir, porque el pensamiento activo es más bien la atención, es esa memoria activa que vale más que la escritura. Porque, aunque ésta forma parte del método, es sólo un útil que sirve para probar lo pensado, es siempre posterior ontológicamente al pensamiento. La escritura es sub-

1 «A l'occasion de quoi je suis bien aise de prier ici nos neveux de ne croire jamais que les choses qu'on leur dira viennent de moi, lorsque je ne les aurai point moi-mẻme divulguées". Discours de fa méthode, en CEures philosophiques. / (1618-1637), edition de F. Alquie, Garnier, Paris, 1963, p. 641.

2 Aféditations..., anres philosophiques, $/ /(1638-1642)$, édition de F. Alquiê, Gamier, Paris, p. 400 . Como señala Genevieve Bolleme, el modelo cartesiano de escritura serd el inatemático, cft. "l.ordre de l'ecrit: Descartes", en Parter d'écrire, Seuil, Paris, 1993, p. 167. Ver también Regla X1I, I, ibid.

3 "L'Entretien avec Burman, texie 4 ", citado por BollèMe, ibid. p. 191.

4 Regla X, ibid.

5 Cfr. Carta a Mersenne, 20 de noviembre de 1629. I, pp. 227-232.

6 Discours de la méthode, ibid, p. 614. O en esta otra cana a Mersenne del 11 de octubre de 1638, a propósi. to de la resolución de un problema de geometria: we tous jure que sans plume ni calculs, arec m senl momem d'atention", II, p. 108. 
sidiaria del método, porque el método lo constituyen propiamente las reglas que han de dirigir el espiritu.

Aunque Descartes va a proponerse limar esa escritura con el cuidado que requiere la publicación, escribir se presentará para él como un proyecto fallido. Por eso Descartes renunció en algún momento a publicar ( $y$, asi, escribir sólo a sus amigos, por el placer de la discusión privada frente a lo enojoso de la disputa pública ${ }^{7}$ ), porque constató el fracaso de aquello que pretendía con esa escritura pulida y trabajada: expresar el orden claro y distinto del pensamiento. Descartes quiere renunciar porque su exigencia no se ha cumplido: las disputas y controversias continuan, lo cual era sintoma, de algún modo, de que la escritura no habia sido capaz de transmitir el mismo orden y verdad que él habia alcanzado con las reglas del método.

Esta escisión entre pensamiento y escritura es una de las diferencias fundamentales que encontramos con respecto a la representación que de la escritura se plantea en lo que Zambrano llama confesión. ${ }^{8}$ Y es que aqui no se trata de construir una escritura controlada, por medio de la cual la verdad fuera transparente, pues se asume desde el comienzo que no hay tal escisión. Si Descartes pensaba la escritura como instrumento que establecia la continuidad del pensamiento y remediaba la debilidad de la memoria voluntaria, en la confesión, al operar la memoria involuntaria, se parte de la intrinseca discontinuidad del pensamiento. Por ello, escribir se presenta aqui como método, porque en el acto mismo de la escritura se revelará la evidencia que se trata de hallar. Siendo la escritura para Descartes, por el contrario, subsidiaria del método, la evidencia que le revelaba el acto de escribir era la de su fracaso.

De tal manera que Descartes manifiesta hacia el final de su vida su renuncia a publicar, pero no a escribir, no a una escritura privada. Cabe sospechar, no obstante, que, más allá de que ello suponga buscar un reposo que le permita seguir instruyéndose e instruyendo su escritura. Descartes desconfia por lo que escribir le revela, por la evidencia que le muestra: el fracaso de lo que le había exigido: la imposibilidad de lograr traspasar la opacidad de lo escrito.

7 «Et parce que je n'ai pas eu la même prudence à m'abstenir d'écrire, je n'ai plus tant de loisir ni tant de repos que j'aurnis, si j'eusse eu l'esprit de me taire [... E E ainsi je crois que le mieux que je puisse faire dorénavant, est de m'abstenir de faire des livres; et ayant pris pour ma devise: (Une mort pénible l'attend / Celui qui, trop connu de tous, / Meurt inconnu de lui méme [Versos de Séneca, el trágico (Thyeste, 400)]), de n'étudier plus que pour $m$ instruire, et ne communiquer mes pensḱes qu'd ceux avec qui je pourrai converser privément». Lettre a Chunut, I novembre 1646, CEnres philosophiques, III (1643-1650), édition de F. Alquie, Garnier, Paris, 1989, pp. $682-683$.

B La Confesión: Género Literario, Mondadori, Madrid, 1988, passim. Este libro se publicó en forma de antculo en 1941 y 1943 en la revists Laminar de México. 